\title{
Analysis of the use of Seismic Dampers in Sri Lanka to Minimize Damages to Constructions in an Earthquake
}

\author{
P.M.S.S.B. Muhandiram \\ Department of Civil Engineering, Faculty of Engineering and Technology, CINEC, \\ Millennium Drive, IT Park, Malabe, Sri Lanka Lanka \\ supulbandaralgmail.com
}

\begin{abstract}
Earthquakes happen all around the world and they have now become a common threat to the mankind. Sri Lanka is also becoming more vulnerable to earthquakes due to recent geological changes. The aim of this study was to present modern methods of constructing earthquake resilient structures in the world and to study the most suitable solutions for Sri Lanka. Earthquake dampers reduce the vibrations and motions of a building during earthquakes. There are many types of earthquake dampers. Base-isolator is where the base is isolated from the building in the time of an earthquake reducing the motion of the building. Viscous dampers act as shock absorbers in the event of an earthquake, reducing the motion of the building. Friction dampers act like brakes due to its friction and reduce the motion of the building. Tuned mass dampers use the concept of inertia to keep the structure still by exerting an equal and opposite motion to the motion of the building. Core - wall method attempts to keep the centre of gravity in the centre of the building. There are many other innovative methods like the levitating foundation which creates a cushion of air between the building and the foundation at the time of an earthquake, seismic invisibility cloak which aims to make the building invisible to seismic waves, smart materials that have a larger elastic range, biomaterials that base their concepts on biological features of some creatures and cardboard tubes which presents a more affordable seismic damping solution. Considering the local conditions, the most suitable methods were studied and the following were concluded. For low and high rise buildings friction dampers, for hospitals - base isolation, for bridges viscous dampers, for stadiums and power distribution lines tuned mass dampers and for towers - core wall method can be proposed.
\end{abstract}

Keywords - Earthquakes, Earthquake dampers, Resistance

\section{INTRODUCTION}

An earthquake is the shaking of the earth's surface due to the release of energy by means of seismic waves from the earth's core resulting from the movement of tectonic plates inside the earth. Earthquakes cause devastations killing thousands of people each year. The loss of property exceeds billions of USD.

"Earthquakes don't kill people, buildings do" [1].

The above phrase explains the fact that majority of the fatalities from an earthquake is not due to the earthquake, but due to the inability of the structures to withstand the earthquake. Therefore, it highlights the importance of using ways to minimize the damages and to assure the structural integrity of the structures in the event of an earthquake. This is where earthquake dampers are of prime importance.

\section{A. Definition of Earthquake Dampers}

Earthquake dampers (seismic dampers / seismic vibration control devices) are instruments that minimize damages to constructions during earthquakes and typhoons (cyclones) which cause these structures to shake, sway and vibrate that can otherwise cause severe structural damages. Earthquake dampers are now widely used in high rise buildings as high rise buildings are prone to extremely high wind loads and the intensity of an earthquake is much severe on a high rise building than on a low rise building. It is also important to note that with the growing trend of "vertical living", it is essential that engineers have a sound solution to shield these constructions from earthquakes and other natural disasters as these constructions would be carrying thousands of lives at a single time.

Some examples for popular buildings considered as engineering marvels due to the technology of earthquake dampers used are Tokyo Skytree and Taipei 101. [2], [3]

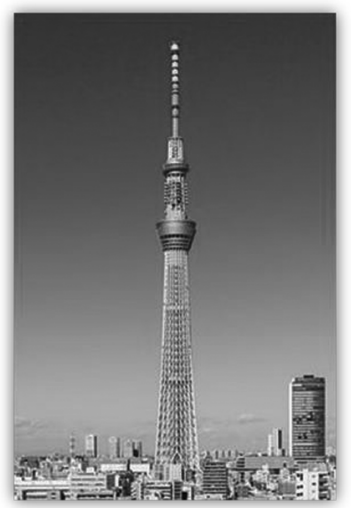

Fig. 1 Tokyo Skytree [4]

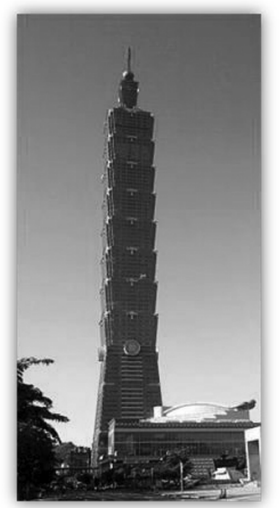

Fig. 2 Taipei $101[5]$

\section{B. Usage of Earthquake Dampers}

There are mainly 4 uses of earthquake dampers.

- To reduce the energy of seismic waves inside a structure in the instance of an earthquake, thus reducing the damages to the building.

- To divide and spread the wave energy between a wider variety of frequencies. The damage to the building becomes severe at an instance where the frequency of the seismic waves of the earthquake becomes equal to the natural frequency of the building. Therefore, by this method, it is made sure that the frequency of the seismic waves is dispersed 
so that the intensities become very small in a particular range of frequencies, so a substantial damage is not done even if the natural frequency of the building is matched with the frequency of the seismic waves.

- To absorb the frequencies of seismic waves which have the same frequency as the natural frequency of the building with the use of mass dampers. [6]

- To reduce the motion of the building in the event of a typhoon (cyclone) which would exert enormous wind loads on the structure. It is important to note here the fact that outer design of the structure can heavily influence the performance of the structure in the instance of high wind loads. If the structure is designed in such a way that the air flow is not objected, the wind load on the structure would be dramatically reduced. Burj Khalifa, the tallest skyscraper in the world has been designed to withstand high wind loads. The rounded surfaces of the structure are letting the air to flow freely on its surface without objecting the flow.

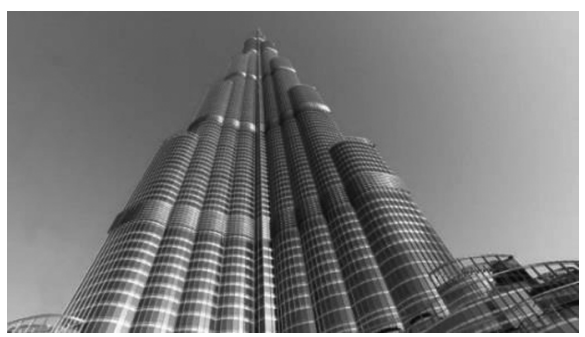

Fig. 3 Burj Khalifa (The rounded design is clearly visible) [7]

\section{Effectiveness of Earthquake Dampers}

The motion inside a high rise building causes greater difficulties for the occupants in the building and repetitive motion would cause the structure of the building to weaken, and subsequently, collapse causing devastation.

The figure 4 below clearly shows how an earthquake damper reduces the motion inside a high rise building in the instance of an earthquake.

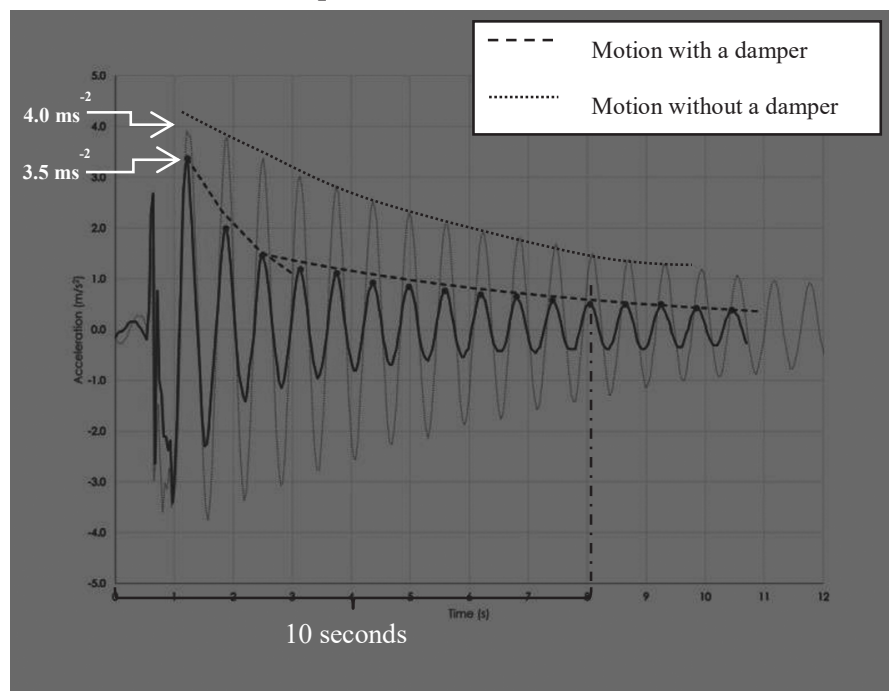

Fig. 4 Effectiveness of earthquake dampers [8] a) The light black curve in figure 4 shows the acceleration of the building in the event of an earthquake without an earthquake damper. The building gets an initial acceleration of about $4 \mathrm{~ms}^{-2}$ in 0.6 seconds [8]. This would be arduous for the occupants of the building as the human body is very sensitive to accelerations. The repetition of this high amplitude decaying motion for about 10 seconds would definitely make the building structure to weaken [8]. It is not the initial acceleration that matters, but it is the repetition of the motion that matters and would weaken the building structure due to its repetition [8].

b) The dark black curve in figure 4 shows the acceleration of the building in the event of an earthquake with an earthquake damper. There is a remarkable difference in the performance of the building. The maximum acceleration is $3.5 \mathrm{~ms}^{-2}$ which is a reduction of only about $12.5 \%$ [8]. However, the most significant change is how quickly the motion decays and the reduction of the amplitude of the motion. This is because the damper depletes the kinetic energy of the building. This reduction in the amplitude of the motion would make the building structurally resilient. [8]

\section{Earthquakes in the Sri Lankan context}

As Sri Lankans, our experience and knowledge about earthquakes are very low as we consider ourselves to be protected from earthquakes. But, recent studies carried out by James Cochoran of the Lamont-Doherty Earth Observatory have clearly shown that this is not the case. [9] Sri Lanka is also becoming more vulnerable to earthquakes as the 'Indo Australian' tectonic plate is splitting and a new tectonic plate boundary is emerging just $500-700 \mathrm{~km}$ from the south - west coast of Sri Lanka. This has also been confirmed by the United States Geological Survey, (USGS) which is one of the most reputed geological institutions in the world. Hence, the possibility of a moderate sized earthquake cannot be ruled out from Sri Lanka as we did in the past.

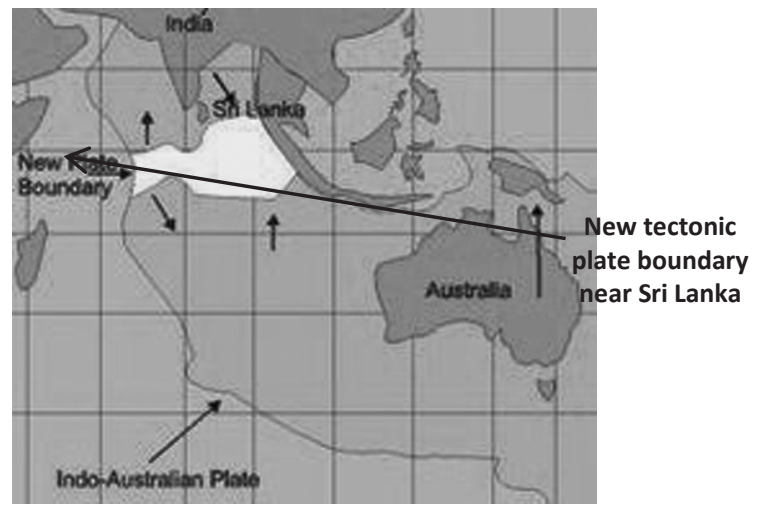

Fig. 5 New tectonic plate boundary that is emerging [9]

Therefore, these circumstances have made it extremely important to construct earthquake resilient structures in Sri Lanka. Hence, the objective of this study was to present the modern methods of constructing earthquake resilient structures in the world and to study the most suitable solutions for Sri Lanka. 


\section{DIFFERENT TYPES OF EARTHQUAKE DAMPERS}

\section{A. Normal Earthquake Damping Technologies}

1) Base Isolation: This is where the foundation and the building are separated by means of some material that allows the substructure (foundation) to move separately without getting the superstructure (building) to move. The most popular material used to separate the building and the foundation is lead rubber bearings. Here, the core is solid lead with layers of steel and rubber around it. Steel plates attach the building and the foundation to the bearings. Therefore, when an earthquake happens, the foundation moves without moving the upper building structure. There are other dampers that use this concept like springs - with damper base isolator and simple roller bearing. These are particularly used in high rise structures where there is a vast spread of the surface area (footprint) of the structure. [10]

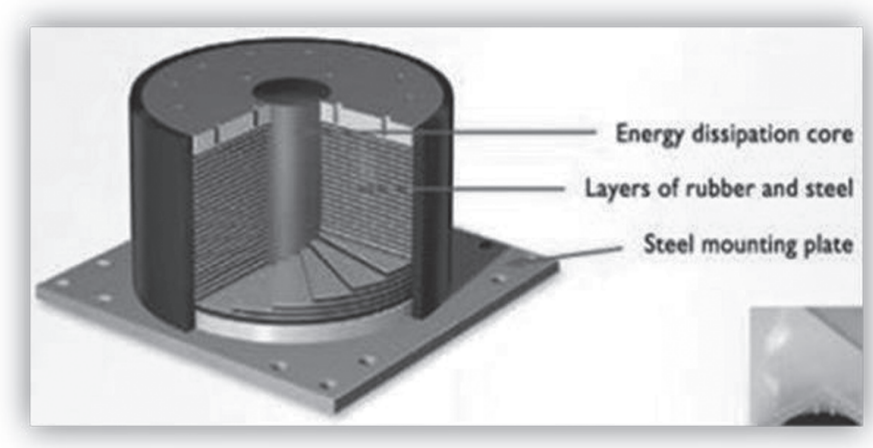

Fig. 6 Interior of a lead - rubber bearing [6]

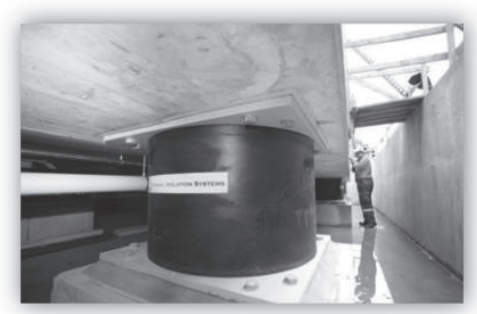

Fig. 7 Lead - rubber bearing in use [10]

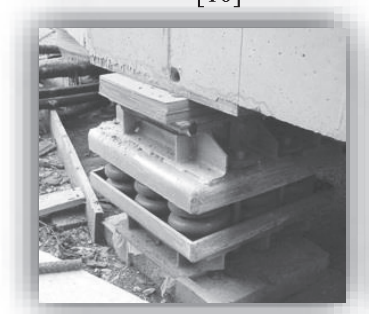

Fig. 8 Springs - with damper base isolator [10]

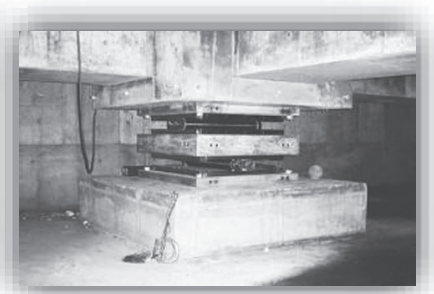

Fig. 9 Simple roller bearing [10]
2) Shock Absorbers (Viscous Dampers): Shock absorbers or viscous dampers are usually fitted in every floor of a building with one end attached to a column while the other end is attached to a beam. Inside the damper, there is a piston head inside a cylindrical arrangement with a silicon based fluid. This fluid has a soaring 'specific capacity of heat' so that it can absorb large amounts of heat. When an earthquake occurs, the piston starts to move and this causes the kinetic energy of the earthquake to be transferred into heat energy inside the piston due to the viscosity of the silicon based fluid. Due to the higher specific capacity of heat, the silicon based fluid can withstand the enormous energy induced by an earthquake. This helps in dissipating the large kinetic energy of the earthquake and slowing down the motion of the building. These are widely used in buildings, but its usage is constrained due to its bigger size and aesthetically unpleasing look.[2], [11]

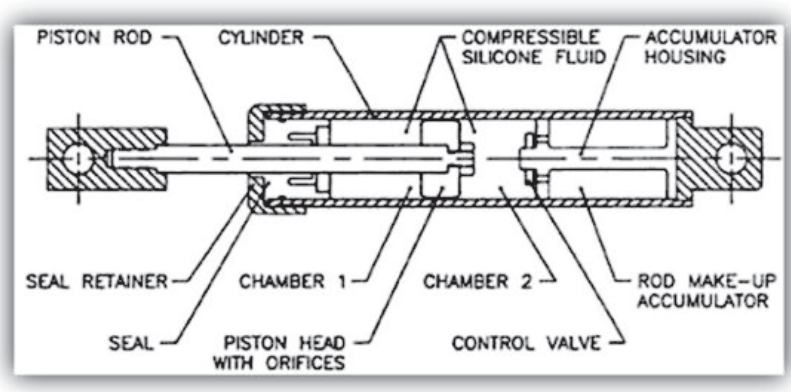

Fig. 10 Interior of a viscous damper [12]

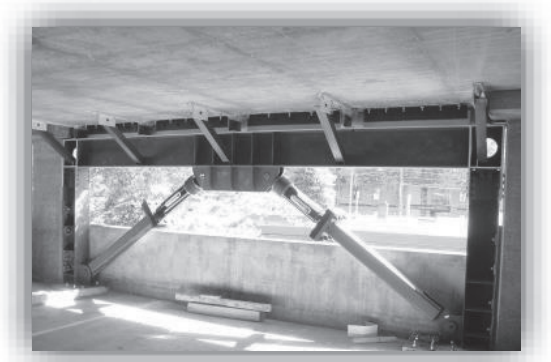

Fig. 11 Viscous damper in use (Aesthetically unpleasing look is evident here) [2]

3) Friction Dampers: The joints of the friction damper are connected together in such a way that they can move on each other. High frictional forces are created between them as the surfaces of the friction damper are made with materials with a high coefficient of friction. Therefore, these friction dampers work like brakes and try to convert the kinetic energy produced by the earthquake to heat energy inside the joints. Friction dampers are not usually used for wind loads as the damper tends to wear out due to friction when doing repetitive movements and these have to be replaced every time an earthquake happens. Therefore, this is not suitable for high rise buildings in earthquake prone areas. [3], [13], [14]
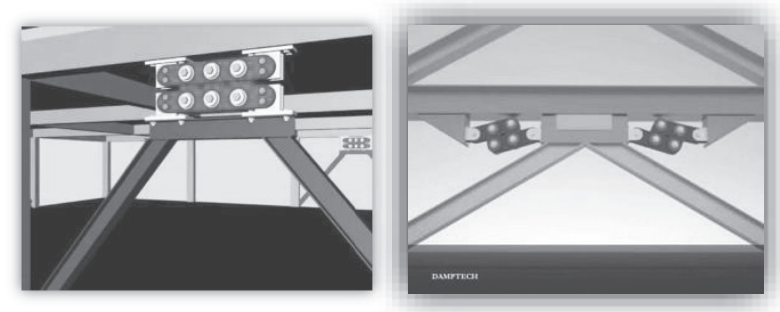

Fig. 12 Friction dampers [3]

4) Tuned Mass Dampers (Harmonic Absorbers): Tuned mass dampers or harmonic absorbers are used in buildings, bridges, stadiums and power distribution lines to prevent motions in these structures due to earthquakes, wind loads or other artificial vibrations. Tuned mass dampers are widely used in skyscrapers 
to prevent discomfort to the tenants due to motion and vibration of the building in extremely high winds and earthquakes. A tuned mass damper is usually an extremely high mass that is hung by steel cables like a pendulum from the top and connected to the building using viscous dampers at its bottom. This setup is usually installed at the highest parts of the skyscraper because the motion is much higher in the upper levels of the building than in the lower levels. The mass damper uses the concept of inertia. Inertia is the tendency of an object to stay in its current state of motion or the aversion of an object to change its current state of motion. As inertia directly depends on the mass of an object, an extremely high mass is used for the damper. Here, when the building sways to the left, the mass damper tries to protect its state of motion (rest) by swaying to the right. This motion exerts forces on the viscous dampers in the opposite direction to the motion of the building and therefore, the kinetic energy of the motion is dissipated as heat energy by the viscous dampers. This results in a much calmer and safer building. Any structure vibrates violently at its natural frequency and this is known as resonating. The word tuned mass damper is specifically used as this mass damper is tuned to the natural frequency of the building. Therefore, the frequency and the amplitude of the motions of the mass damper are nearly equal to that of the building. These result in an equal and opposite push being exerted on the building by the mass damper minimizing the horizontal displacement of the building during times of earthquakes and typhoons (High winds). Taipei 101 skyscraper has a 660 tonnes tuned mass damper and it has been able to successfully withstand many earthquakes and typhoons since its inception in 2004. This is the only place that the tuned mass damper is open for the public to see. Tuned mass dampers are widely used in skyscrapers. The main problems with tuned mass dampers are the higher space needed for the damper and the higher maintenance cost. [5], [8], [12]

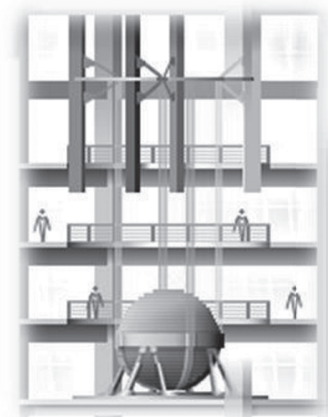

Fig. 13 Tuned mass damper inside Taipei 101 skyscraper (Outside view) [16] [15]

5)

- Wall Method (Central Shaft Method): Core wall method is constructing a thick and solid reinforced concrete column (pillar) through the centre (heart) of the building. This helps the centre of gravity of the building to be located near the centre of the building and this also acts as a backbone for the

building. Human backbones keep humans straight and it also helps in balancing our body when some external unbalanced force is applied on us. The core - wall acts in the same manner and helps in reducing the motion and vibrations due to earthquakes and wind loads. Ancient Japanese earthquake resistant constructions have also been constructed using this concept. Tokyo Skytree, the tallest broadcasting tower in the world has been constructed using this technology. Here, there is an outer steel structure and this outer structure is directly attached to the main internal pillar up to the first $125 \mathrm{~m}$. After that, the outer structure is attached to the main internal pillar using viscous dampers. This is due to the fact that the effect of motion is relatively higher in the upper levels of the building. This setup helps to dissipate the kinetic energy that enters the building in the event of an earthquake or typhoon by converting the kinetic energy into heat energy inside the viscous dampers. This method is widely used in towers and even in normal high rise buildings as well. [17], [18]

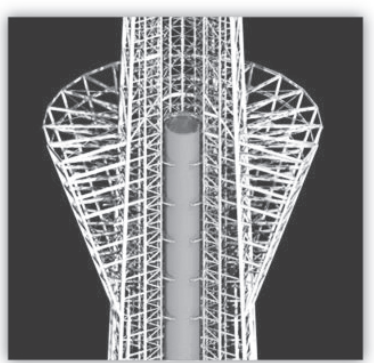

Fig. 15 Core - wall (Central pillar) of the Tokyo Skytree [17]
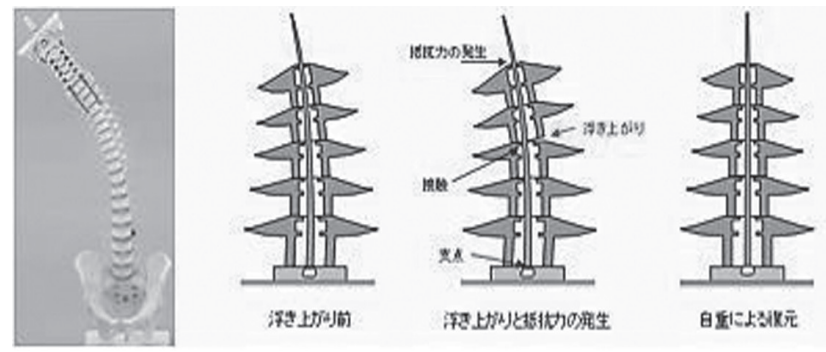

Fig. 17 How the concept of the backbone has been used in ancient Japanese earthquake resistant constructions [4]

B. Innovative Earthquake Damping Technologies

1) Base Isolation - The Levitating Foundation: Base isolation has been combined with innovative technology by some Japanese engineers and they are now developing a system which literally makes the building to levitate in the event of an earthquake. Sensors are fixed to the building to get notified when an earthquake happens. Immediately, with the use of air compressors, the building is lifted up and when the effect of the earthquake is materialised, the building would be floating on a cushion of air. When the earthquake subsides, the building comes back on to 
its foundation. This would mean that the occupants of the building would not feel that an earthquake has happened. However, this design has a long way to go before it can be actually used due to the effects of the motion of the ground relative to the building and due to high maintenance costs as many sensors are used. [19]

2) Seismic Invisibility Cloak: Seismic waves have 2 main types as body waves and surface waves. Body waves travel faster inside the Earth than the surface waves which travel on the surface of the Earth. Surface waves cause almost all the destructions caused by an earthquake. There are 2 main types of surface waves. They are Love waves and Rayleigh waves. Love waves cause horizontal motions while Rayleigh waves cause vertical motions which are the most destructive. Engineers are now researching on making constructions invisible to these surface waves, Rayleigh waves in particular. When considering about the behaviour of waves, a stream of water would flow around a rock and continue its journey. Engineers are using that same preliminary concept for the seismic invisibility cloak. The concept is to bury 100 concentric plastic rings beneath the building's foundation. When the seismic waves enter the rings from one end, they are unable to transfer their kinetic energy to the foundation. Therefore, seismic waves would simply go around the rings and continue their journey just like how a stream of water would go around a rock and continue its journey. This concept has several drawbacks. The main drawback is the amount of sensitive calculations along with a number of estimates that are needed to exactly design the dimensions of the plastic rings and other apparatus used. The other main drawback is the fact that this can increase the harm to the structures surrounding the damped structure because the distribution of kinetic energy by the seismic waves is made unequal by the plastic rings. [19], [20], [21]

3) Shape Memory Alloys (Smart Materials): Normally, steel and concrete which are the 2 widely used materials in building construction reach their plastic ranges quickly and fail due to the permanent deformations that happen in the event of an earthquake. But, smart materials have a much larger elastic range. Therefore, they can withstand extreme motions (deformations) and return back to their original position without failing in the process. Nickel Titanium alloy is such a smart material. This can be used in the construction of bridges to minimize damages that happen to bridges during earthquakes. [19]

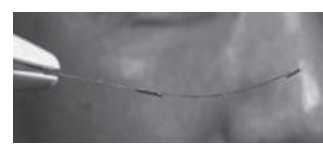

Fig. 18 Shape memory alloy tube [19]

4) Biomaterials: Engineers are now focusing on characteristics of some molluscs and spiders to develop much more efficient earthquake dampers. Molluscs who stick to different surfaces like rocks secrete sticky fibres known as byssal threads for this purpose. These sticky fibres contain some components which are stiff and rigid, but there are also components which are flexible and elastic. These flexible and elastic components in the byssal threads enable the mollusc to stay stuck to one surface as the kinetic energy applied by the sea waves is dissipated by the flexible components. Engineers are trying to use this concept to come up with innovative earthquake damping technologies. On the other hand, there are some spider webs which show very interesting characteristics. When strains are applied, they are initially stiff, then flexible and once again stiff. This behaviour shows an invaluable feature and engineers along with biological scientists are trying to understand the composition of the structure of these spider webs to come up with much improved earthquake dampers for the future. [19], [22]

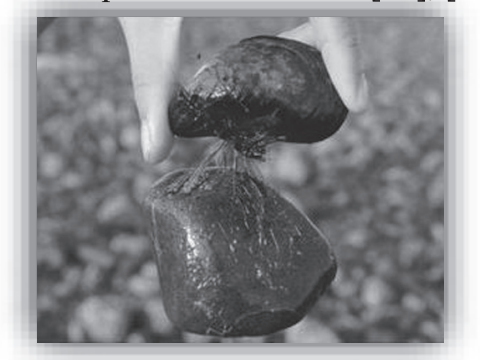

Fig. 19 Byssal threads [22]

5) Cardboard Tubes: All the above mentioned methods are very expensive to set - up and maintain. Therefore, engineers have come up with much cheaper methods to minimize damages to buildings during earthquakes. One such method is the use of giant cardboard tubes reinforced with timber beams. As cardboard and timber have a much larger elastic range in comparison with concrete which is a brittle material, they would be able to withstand vibrations and motions much better than concrete. Another advantage is the light weight of the structure. Even if the structure was to collapse, number of fatalities would be much lower due to the light weight of the structure. The main outstanding advantage is the lower cost of the structure. But, this concept would only be useful in normal buildings without any stories and this design can be aesthetically unpleasing as well. [19]

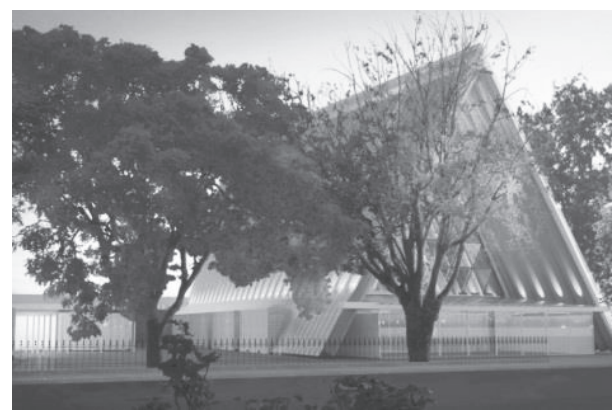

Fig. 20 A structure designed using cardboard tubes [19]

\section{CONCLUSIONS}

Earthquakes happen all around the world and are becoming a common threat to the mankind. The above stated technologies and mechanisms can be used to make the lives of 
people living in this planet much better as they are instrumental in preserving human life. It should also be noted here that the above discussed mechanisms are some of the major types and there are many more technologies and concepts that can be helpful in minimizing damages to constructions during earthquakes.

As stated in the introduction of this paper, Sri Lanka is also becoming more vulnerable to earthquakes due to the recent geological changes. Therefore, the suitability of the above discussed methods in Sri Lankan context was studied and the following information was obtained.

Base isolation - This method is suitable for high rise buildings with a vast area. In the Sri Lankan context, this is more suitable for major hospitals and high rise commercial buildings that have a wide geographic spread. This method can even be used to make existing buildings earthquake resistant. The issues of this method are the high initial cost of the damping devices and the lack of expertise about earthquake damping in Sri Lanka.

Viscous dampers - In Sri Lankan context, these can be used for high rise buildings, bridges and overhead railroads as these dampers are robust even in rough environments. The major issues of this method are the high initial and maintenance cost, lack of expertise about earthquake damping in Sri Lanka and the aesthetically unpleasing look of the large dampers which are fixed in every floor of the high rise building.

Friction dampers - Friction dampers are worn out every time an earthquake happens and they should be replaced. In the Sri Lankan context, these seem to be the most ideal solution as Sri Lanka does not experience frequent earthquakes and the cost of these dampers are much lower in comparison to the other earthquake damping technologies. However still, a proper cost - benefit analysis should be carried out considering the probability of an earthquake and future replacement costs along with the aesthetically unpleasing look of these dampers.

Tuned mass dampers - This type of dampers are mainly used in skyscrapers to make the structure resilient to earthquakes and typhoons. In Sri Lanka, as we do not have skyscrapers, this type of damping is not very appropriate. The cost of large tuned mass dampers is prohibitive as well. But, smaller tuned mass dampers can be fixed in sports stadiums to protect these structures in the event of an earthquake and in the event of heavy vibrations in the structure due to enthusiastic sports fans. These can also be fixed in high tension power distribution lines to protect them from earthquakes and extreme wind loads. The lack of expertise about these technologies is an issue.

Core - wall method - This method is mainly used in high rise towers. Sri Lanka only has the Lotus Tower as a high rise tower and this tower utilizes the lift core as their core wall. This design has only considered the effect of heavy wind loads due to its height and has not primarily considered the effect of earthquakes although effects of normal artificial vibrations has been considered. If Sri Lanka is to go forward with another tower project, considering the effect of earthquakes in the design stage and utilising the tried and tested core wall method to make the structure earthquake resilient would be crucial.

The innovative new technologies mentioned in this paper are still in the research stage and therefore are not suitable for Sri Lanka as yet.
Therefore, from the above findings, the following were concluded considering the local conditions.

The most cost effective and feasible yet safe solution is friction dampers for normal low rise and high rise buildings.

Base isolation is suitable for buildings with a vast area. This can be used for hospitals as the cost of the damper is justified by the importance of the structure.

For bridges, viscous dampers are the most suitable as they can withstand considerable vibrations and motions. Friction dampers are not recommended due to the wear and tear within the dampers due to the vibrations that happen due to the normal loads imposed on the bridge in its service period.

For sports stadiums and high tension power distribution lines, small scale tuned mass dampers are recommended which would be very useful in preserving these structures in earthquakes, artificial vibrations and heavy winds (typhoons).

For towers, the core - wall method can be used and it would be very useful to protect the structure from earthquakes and to dissipate the high wind loads applied on the structure.

The design of the structure also plays an important role when it comes to earthquake resistance. Therefore, the structural design is also crucial for earthquake resistance.

Sri Lankan construction industry should understand the importance of directing their focus towards this new development in the geological surrounding of Sri Lanka and should further focus on the precautionary measures for an earthquake without waiting to take action after a catastrophe has taken place which is like 'closing the stable door after the horse has bolted.'

\section{METHODOLOGY}

Raising awareness about this threat of potential earthquakes would mean that more professionals would incorporate this threat in their designs, which could lead to greater savings in lives and property if an earthquake actually happens.

Pushing Sri Lankan construction industry towards the modern sophisticated technologies would make sure that threat of earthquakes are properly considered, identified and quantified and modern preventive measures are taken to preserve the constructions.

\section{REFERENCES}

[1] STOCKTON, N., 2015. Earthquakes Don't Kill People, Buildings Do

[2] 21st Century Builder, 2014. Energy Dissipation Devices Earthquake Resistant Design Technique.

[3] Anon., 2017. Wikipedia.

[4] Kakidai, 2014. Tokyo Skytree in 2014.

[5] Thompson, A., 2007. Taipei 101.

[6] Teratec, 2016. Seismic Isolation.

[7] Anon., 2017. YouTube.

[8] Hillhouse, G., 2016. Tuned Mass Dampers in Skyscrapers

[9] Dissanayake, C., 2010. Earthquakes and tsunamis: How vulnerable is Sri Lanka?.

[10] .Civil Digital, 2017. Base Isolation System: An Outline on Principles, Types, Advantages \& Applications.

[11] The constructor, 2013. Seismic Dampers.

[12] The constructor, 2015. WHAT IS TUNED MASS DAMPER AND ITS APPLICATIONS?. 
Technical Analysis of the use of Seismic Dampers in Sri Lanka to Minimize Damages to Constructions in an Earthquake

[13] A.V. Bhaskararao, R. J., 2006. Seismic analysis of structures connected with friction dampers. Engineering Structures, 04, 28(5), pp. $690-703$.

[14] Avtar S. Pall, R. P., 1996. Friction - dampers for seismic control of buildings "A Canadian experience". Issue 497.

[15] Anon., 2017. [Online]

[16] Dreamstime, 2017. Dreamstime.

[17] Elizabeth, 2014. Tokyo Skytree Town Projection Mapping 2014.

[18] Okuchi, A., 2016. The Oldest and Newest Tower in Japan Share Same Technology.

[19] HARRIS, W., 2017. 10 Technologies That Help Buildings Resist Earthquakes.

[20] Barras, C., 2009. Invisibility cloak could hide buildings from quakes.

[21] M. Brun, S. G. A. B. M., 2016. Achieving control of in-plane elastic waves. Applied physics letters, 94(6).
[22] Buehler, Z. Q. M. J., 2013. Impact tolerance in mussel thread networks by heterogeneous material distribution. Nature Communications, 23 07.4(2187).

[23] Rafiee, M., 2012. Smart Materials Improve Earthquake-Resistant Bridge Design.

[24] Merali, Z., 2012. How Do You Make a Building Invisible to an Earthquake?

[25] Hamid Saadatmanesh, M. R. E. L. J., 1997. Repair of EarthquakeDamaged RC Columns with FRP wraps. ACI STRUCTURAL JOURNAL, 94(20), pp. 206-214. 